\title{
MEDALLA DE HONOR DE LA RANME: CAYETANO MARTÍNEZ DE IRUJO
}

\author{
Cayetano Martínez de Irujo \\ Duque de Arjona y Conde de Salvatierra
}

Excmo. Sr. Presidente de la Real Academia de Medicina, Excmos. Sres. Académicos, de número, Ilmos. Sres. Académicos correspondientes Sras. y Sres., queridos amigos todos.

Luciendo la levita de las grandes ocasiones, con el orgullo de pertenecer a la familia que pertenezco, de tener los padres que he tenido y sobretodo de compartir estos momentos con las personas que quiero y que me quieren, es un verdadero honor entrar a formar parte de alguna manera de esta prestigiosa academia, donde por encima de todo prima entre sus miembros lo más importante para mí en la vida: La Humanidad.

Salvadores de vidas, comprometidos con la investigación y el progreso de la ciencia, la medicina, las intervenciones quirúrgicas y demás servicios en beneficio del ser humano, incluso diría de todo ser vivo.

Al igual que muchos de mis antecesores es difícil de expresar lo que siento al ser honrado por una academia, y en especial por esta Real Academia de Medicina, que además me ha salvado la vida cuando tocaba la muerte ya con las manos, gracias a uno de sus miembros más destacados el Profesor y eminencia, D. Enrique Moreno, ¡mi queridísimo Enrique! Su sabiduría, dedicación, disciplina, sacrificio y compromiso se sumaron a mi valentía, capacidad de sufrimiento, fuerza, fe para salir adelante, ser la persona que soy hoy en día.

A continuación os voy a relatar brevemente lo que ha sido la transición de la Casa de Alba en el siglo XX y principios del siglo XXI. Tras el largo y fructífero mandato de Cayetana Fitz-James Stuart XVIII Duquesa de Alba, al actual Duque D. Carlos Fitz-James Stuart XIX Duque de Alba.

En el año 2009, justo después del día de Reyes, a principios de enero, la Duquesa de Alba entregó una carta sellada con lacre y dirigida todos sus hijos, en la que se dirigía a ellos por sus respectivos títulos, entregándosela al entonces administrador general de la Casa, D. Gerardo Herranz y ordenándole que la abriese y se la leyera a todos y cada uno de ellos. Esta carta está impresa en mi libro, "De Cayetana a Cayetano". Por ello solo me limito a esquematizar su contenido. Les comunicaba a todos que era su decisión que su hijo Cayetano pasara por varias razones a ocuparse desde ese mismo momento de las tres empresas agrícolas de la Casa; Salamanca, Córdoba y Sevilla y cerraba el texto diciendo: "Muchas gracias por ayudarme, un beso para todos, Mamá".

Esta carta supuso una gran sorpresa para todos, sobre todo para mí. Al irla leyendo cada uno, se sucedieron diversas y algunas violentas reacciones de sorpresa, en algún caso, cierto shock. Ese episodio, fue sin duda, el comienzo de una nueva época; la transición y sin duda alguna de que solo se encuentre en este maravilloso salón de actos mi único hermano Fernando al que siempre quise por encima de todo, con el que conviví codo con codo infancia y adolescencia y al que hoy agradezco su inteligencia emocional, su honestidad y su enorme generosidad. Posteriormente fui llamado por Carlos, mi hermano mayor a su cuarto en donde tuvimos una conversación a fondo sobre la nueva situación. Ante todo le di mi palabra de que contaba con mi lealtad y siempre estaría informado de todo esporádicamente.

Emprendí la marcha en tal ardua tarea pues la parte agrícola era la más descuidada y contaba con una estructura compleja y ciertamente desorganizada que en los últimos 30 años había estado manejada por administradores y técnicos locales que habían campado a sus anchas. Tres explotaciones y 28 fincas que en su totalidad suponían unas $35 \mathrm{mil}$ hectáreas. Tras un año de trabajo continuado y muy duro empecé a reorganizar, limpiar deuda y ordenar, junto a un pequeño equipo de abogados, técnicos y algún encargado que comencé a cambiar en función de las posibilidades. Cayetana me seguía de cerca y justamente pasado este año, de nuevo a principios de enero, estábamos almorzando con ella, los cuatro hermanos que vivíamos en Liria, Carlos, Fernando, Eugenia y Cayetano. Después del café se levantó y dijo: "Os quiero comunicar que a partir de ahora, Cayetano no so/o va a llevar el campo, sino toda la Casa: Fundación, administración y funcionamiento de palacios y demás casas. Carlos, especialmente a ti, te pido que cooperes y ayudes, pues eres el mayor y el primogénito". Se despidió y se marchó esta vez sin darnos el beso correspondiente de despedida que era lo habitual. Hubo un silencio frío y con gestos confusos fuimos desfilando del salón a

\section{Autor para la correspondencia}


nuestros respectivos aposentos por los pasillos y escaleras. A mí, me costó subir las escaleras hacia mi cuarto y una vez llegado a él, caí desplomado sobre una de las butacas, con la mirada perdida y una profunda sensación de soledad y temor...

Al poco rato sonó el teléfono de mi cuarto, cogí y era ella. Me pidió que bajase a su cuarto, quería hablar conmigo. Al llegar llamé a la puerta, como siempre hacia desde pequeño, entré y me senté en la única silla que se podía utilizar. Mudo y atónito escuche atentamente.

"Cayetano, he seguido de cerca tu dirección durante este año de todo el campo. Has ganado mi confianza para que deposite en tus manos, lo más importante de mi vida, al margen de vosotros, mis hijos. Eres valiente, inteligente y siempre consigues lo que te propones. A partir de ahora, despacharas todo únicamente conmigo sin contar con nadie más. Ahora me tengo que ir al cine." Me dio un beso con cálido abrazo y me fui por donde había venido igual de mudo y perplejo.

Desde ese mismo instante fui plenamente consciente de la misión que se me había encomendado y como cuando estás en la puerta de entrada de una pista de competición donde representas a tu país, a tu equipo y sobre todo a ti mismo, me crecí por dentro con orgullo y valentía ante la adversidad que se me avecinaba e inmediatamente me dispuse a planificar en mi cabeza el desembarco en tan enorme estructura.

Comencé por informarme bien sobretodo de lo esencial: funcionamiento y situación económica, estructuración patrimonial, número de personal en cada zona, y referencia de los mismos. Me encontré con un cierto desorden, una estructura bien formada pero algo obsoleta y una situación económica muy delicada pero reconducible. Cuando me fui trasladando a cada zona de palacios o casas, eso me permitió ir conociendo al personal que todavía no había conocido a fondo, como ya había hecho con las zonas de campo.

Había mucho descontrol, manejo autónomo y sobretodo una descomunal corrupción.

Es imposible sobrevivir con un pequeño imperio semejante, al estilo del siglo XIX o principios del $\mathrm{XX}$, en estos tiempos, especialmente en un país como España, donde nuestro "Lazarillo de Tormes" se ha convertido en un pequeño o gran delincuente, según sus posibilidades y permisión. Frenar, empezar a controlar, reorganizar y enderezar todo lo antes citado, os digo que fue un duro trabajo. Paralicé mi carrera deportiva y me faltaban horas y días para viajar por España empapándome a fondo con todo.

Quiero dejar bien claro que, al igual que como mi madre, me ayudó el gran consejo de Amancio Ortega. Mandara yo solo, uno, rindiendo cuentas e informando a la dueña. Eso sí, jamás deje de informar a mi hermano Carlos, primogénito de la Casa. Utilizaba tres vías para no perder la marcha necesaria que requería la regeneración. Parte se la informaba el administrador general, otros asuntos, le consultaba, puesto que su conocimiento sobre ellos era superior al mío, y una tercera, le sugería y al cabo de poco tiempo, volvía con su aprobación como propia. Además, hubo muchísimas peticiones extras, que me pedía como personales y yo convencía a nuestra madre. La lealtad por mi parte fue absoluta, a la Duquesa y a su primogénito pues al fin y al cabo iba irremediablemente ligada.

Todo siguió su curso, viajes, continuas gestiones con alcaldes, diputaciones, trabajadores, empresas proveedoras, en fin, desde el mismísimo presidente del gobierno hasta el Sindicato Andaluz de Trabajadores, dirigido por los sindicalistas obreros Gordillo y Cañamero, con quien compartí varias jornadas y reuniones, incluyendo visita oficial a Marinaleda, toda una experiencia de aprendizaje vital a fondo.

El gran buque, que en cierta manera había hincado el morro de proa en la navegación de la mar, se le habían tapado las vías de agua, remodelado las piezas más devastadas en sus motores, reparado las partes que impedían su marcha y relanzaba síntomas claros de volver a navegar, con el flamante estandarte de su historia, de nuevo derecho y firme, rumbo al futuro moderno.

A principios del 2011, nos sorprendió un hecho totalmente inesperado. Carlos mi hermano mayor me comunicó que nuestra madre tenía novio y que había oído que contáramos con su firme voluntad de contraer matrimonio. Nuestra sorpresa fue

monumental, contando con los más de veinte años que supuso la paralización de la Casa tras su segundo matrimonio con Jesús Aguirre. Ello nos llevó, y digo nos porque a partir de ese momento trabajé verdaderamente unido al primogénito puesto que a nuestro entender, peligraba la continuidad sana de toda la estructura, y me dediqué a buscar una solución rápida, eficaz y viable. Consultando con personas de relieve como Luis Maria Anson, Felipe González o Amancio Ortega, conseguí llegar a una conclusión definitiva que emanó de la tenacidad, determinación y buen análisis en tan delicada situación. Les confieso a ustedes, en este solemne y prestigioso acto, que la llegada del tercer marido de Cayetana, fue una bendición de Dios, de nuestro padre y de la propia historia, pues se llevó a cabo el cambio de herencia a donación voluntaria, uno de los hitos más importantes en esta histórica familia. Eso permitió la transición de la Casa al siglo XXI con la mayor discreción, buen hacer y excepcional profesionalidad de un pequeño equipo de gente, algunos profesionales añadidos que se comportaron con el mismo sentido de la historia y la connivencia, apoyo y ejemplaridad de Alfonso Diaz Caravantes, al cual le debemos este histórico proceso así como la felicidad de nuestra madre en los años posteriores, hasta su fallecimiento.

No fue fácil, abordar este asunto con la Duquesa. Quién le planteaba a una persona con su fuerza, carácter y personalidad, donar su patrimonio en vida, quedándose con el usufructo y goberna- 
bilidad, pues me tocó a mí, la persona que ella había elegido basada en su máxima confianza. Era sumamente delicado, si este hecho salía a la luz manejado por ciertos medios de comunicación yo me hubiera visto relegado, repudiado y considerado un traidor y todo se hubiera ido al traste.

Sin embargo, la estrategia sutil que diseñamos en el trayecto de AVE Madrid-Sevilla, mi abogado Emilio Ramirez y yo, acompañado por la suerte del destino y las pasionales ganas de casarse con Alfonso de Cayetana nos llevaron a una satisfactoria decisión por su parte. Lo explico con detalle en nuestro libro, de Cayetana y mío. En tres meses, algo que hubiese tenido que durar entre 8 y 12 meses, a tal día como el 4 de Julio de 2011, se valoró, organizó y llevo a cabo la donación; la cual hizo que cada hijo recibiese lo estipulado por ella en el testamento y sin ninguna duda, fue la salvación del patrimonio y su garantía de continuidad en el futuro.

A partir de aquí, todo fue no más fácil, pero si más fluido. Contaba con la generosidad honesta y el apoyo incondicional no solo de mi madre, sino también de su nuevo marido. Desde esas fechas hasta su triste fallecimiento el 20 de Noviembre de 2014, se trabajó muy duro y principalmente se abordaron las deficiencias más importantes; la reestructuración dentro de lo posible, reorganización de personal y disminución del mismo aprovechando recursos. También se luchó firmemente contra la corrupción interna y se crearon nuevas fuentes de ingresos para intentar paliar la deuda y minimizar el gran decalaje entre gastos e ingresos. Se contaba con grandes recursos, un patrimonio artístico único, un archivo de valor incalculable. Por el contrario, había que soportar las ataduras, en mi opinión de patrimonio nacional y la dificultad de acción por parte de algunas instituciones del Estado. No recibes ni un euro de ayuda a

lo largo de tu historia, pero además te dificultan y prohíben acciones lícitas con tu patrimonio de forma legal para poder sostenerlo. Aun así, hicimos alguna venta muy suculenta (Rateau) y se crearon: las exposiciones, los eventos acotados en los palacios y la marca de productos de alimentación con veinticuatro registros más. Todo ello, fue realmente positivo y aumentó los ingresos así como redujo la deuda a una cantidad muy asumible para la estructura. Siempre pensaré, que me faltaron al menos un par de años más para terminar de estabilizar el nuevo proceso y sus grandes cambios de modernización, los cuales Cayetana entendió y aceptó con la inteligencia natural y única que poseía junto a su extraordinaria y singular adaptación a la modernidad.

Toda gran hazaña conlleva un alto precio y yo ya lo he pagado con creces. No obstante viviré siempre con la cabeza muy alta por el orgullo de haber sido la persona escogida por la Duquesa Cayetana para llevar a cabo una de las gestiones más importantes en los 600 años de historia de la Casa De Alba. Con el enfoque actual de estrategia y gestión, que ha significado un cambio de 180 grados con el cual yo no puedo estar de acuerdo, aunque lo respeto.
Pero, ya no me corresponde a mi juzgarlo, si no a la historia..

Muchas gracias.

\section{DECLARACIÓN DE TRANSPARENCIA}

El autor/a de este artículo declara no tener ningún tipo de conflicto de intereses respecto a lo expuesto en el presente trabajo.
Si desea citar nuestro artículo:

Martínez de Irujo C. Medalla de Honor de la RANME: Cayetano Martínez de Irujo. An RANM. 2021;138(01).supl01: 14-16. D0I: 10.32440/ar.2021.138.01.supl01.art02 